\title{
Study on semen analysis in the evaluation of male infertility in coastal Karnataka, India
}

\section{Pradeep Ganiga*, Shivakumar Pujeri}

Department of Obstetrics and Gynecology, A. J. Institute of Medical Sciences and Research Center, Mangaluru, Karnataka, India

Received: 21 May 2018

Accepted: 26 May 2018

\section{*Correspondence:}

Dr. Pradeep Ganiga,

E-mail: pradeepganiga@gmail.com

Copyright: ( ) the author(s), publisher and licensee Medip Academy. This is an open-access article distributed under the terms of the Creative Commons Attribution Non-Commercial License, which permits unrestricted non-commercial use, distribution, and reproduction in any medium, provided the original work is properly cited.

\section{ABSTRACT}

Background: According to current recommendation a couple has to be evaluated if they fail to achieve pregnancy within one year of unprotected regular intercourse. The current incidence of infertility is around $15 \%$ which is increasing because of various factors including delay in attaining first pregnancy. The male partner evaluation includes detailed history and examination including the sexual history and semen analysis. Observational study performed on patients with primary and secondary infertility. The detailed semen analysis evaluation done in addition to notifying brief sexual history and chronic medical ailments like diabetes.

Method: After proper counselling, and obtaining consent, the patients were made to collect the semen sample in a room attached to the andrology lab. Detailed evaluation of each sample was done. Prior to this procedure, relevant information like occupation, age of the patient, duration of abstinence, coitus frequency and presence of chronic medical ailments like, diabetes mellitus and chronic hypertension were noted.

Results: The study, done in a tertiary care centre in coastal Karnataka, revealed that a majority of the patients were in the age group of 25-30 years with a larger group of patients having liquefaction time of <20minutes and $25 \%$ were in the oligospermia group.

Conclusions: Semen analysis is an indispensable diagnostic tool in the evaluation of the male partner of infertile couples in addition to brief sexual history and occupational history.

Keywords: Coitus frequency, Liquefaction, Semen analysis, Sperm concentration, Sperm morphology

\section{INTRODUCTION}

Infertility is a condition with psychological, economic, medical implications to the couple resulting in decreasing the quality of life, with a strong emphasis on child bearing. According to WHO infertility is a disease of reproductive system defined by failure to achieve the clinical pregnancy after 12 months or more of regular unprotected intercourse. It can also be defined as failure of couple to conceive after 12 months of regular intercourse without the use of contraception in women $<35$ years, and after 6months of regular intercourse without the use of contraception in women $>35$ years.
As per the WHO, the overall prevalence of primary infertility ranges between $3.9 \%$ and $16.8 \%$. Also, the estimates of infertility vary widely among Indian states from $3.7 \%$ in UP, Himachal and Maharashtra, to $5 \%$ in AP and $15 \%$ in Kashmir. Moreover, the prevalence of primary infertility has also shown to vary across the tribes and castes within the same region in India. ${ }^{1}$

It was reported that $40 \%$ of infertility cases were related to men, $40 \%$ women and $20 \%$ both sexes. According to a multicentric study conducted by WHO from 1982 to $1985,20 \%$ of cases were attributed to male factors, $27 \%$ had causal factors identified in both the partners. In 
Indian couples seeking treatment, the male factor is the cause of approximately $23 \%$. A recent report on the status of infertility in India states that nearly $50 \%$ of infertility is related to the reproductive anomalies or disorders in male. In addition, overall $25 \%$ of infertility cases, no detectable cause can be traced after routine tests, which leaves the case as unexplained infertility. The aetiological factors associated with male infertility are anatomical, developmental, seminal, hormonal, immunological and environmental factors. ${ }^{2}$

Semen analysis is the primary assessment tool to evaluate potential male infertility. It is still a fundamental step for exploring testicular function and gives an orientation to the clinician and helps him establish a diagnosis. Moreover, after a treatment it can be one of the monitoring tools to show if there's any improvement or not.

A good interpretation of the different sperm parameters correlated with medical history of the patient and his clinical file can be very informative and give the good clues for an adapted treatment. It gives an orientation for further semen exploration like a migration survey test in low sperm count value. So, the aim of the study is to determine the pattern of abnormalities in the male partners in couples dealing with infertility.

However, it is to be noted that the evaluation of male infertility is not limited to a simple semen analysis, as it has to be complemented with a proper physical examination, a comprehensive history taking, and relevant endocrine, genetic and other investigations. ${ }^{3}$

\section{METHODS}

The present observational study was conducted at a tertiary care medical college from January 2017 to December 2017. A total of 100 male infertile patients who have come to the OBG department for the evaluation of primary or secondary infertility were counselled for semen analysis after clinical examination. With the semen analysis, brief sexual history including coitus frequency, period of abstinence, age of the patient, chronic medical ailments like diabetes mellitus and hypertension were noted in the andrology laboratory which is attached to OBG department. Semen was collected in a private room which is attached to andrology laboratory by masturbation after noting the number of days of abstinence.

Samples were delivered at the earliest to the technical staff and analysed by the manual method. Analyses done were volume, viscosity, sperm concentration, motility, morphology according to WHO guidelines on semen analysis. A total of 100 cases were studied.

\section{Inclusion criteria}

- $\quad$ Primary and secondary infertility
- Men who had normal genitalia

- And not undergone any genitourinary surgeries, herniorrhaphy/hernioplasty in the recent past.

\section{Exclusion criteria}

- Below the age of 18 and above 55 years of age were excluded

- After obtaining the semen analysis report patients were instructed to get required treatment.

\section{RESULTS}

Data from all the cases of infertility who had undergone semen analysis in andrology laboratory attached to OBG department at AJ Institute of Medical Sciences and Research Center, Mangaluru from January 2017 to December 2017. A total number of 100 patients were included in the study. The details of the patients including age, period of abstinence, coitus frequency, presence of medical ailments like hypertension and diabetes mellitus, history of smoking and detailed semen analysis reports were collected and tabulated.

Table 1: Age-wise distribution of cases in percentage.

\begin{tabular}{|l|l|}
\hline Age group of male partner & \\
\hline $20-25$ years & 6 \\
\hline $25-30$ years & 32 \\
\hline $30-35$ years & 21 \\
\hline $35-40$ years & 26 \\
\hline 40 and above & 15 \\
\hline
\end{tabular}

In this observational study majority of the patients were belonging to 25-30 years of age (32\%), second commonest age group was between 35-40 yrs of age and the least number of cases was reported in 20-25 years age group. Around $15 \%$ patients were belonging to 40 and above age group. As per the research the male partner fertility status is independent of age related risk but in the female, it is a well-defined entity, where advanced age has a direct impact on fertility (Table 1).

Table 2: Coitus frequency per week in the study group in percentage.

\begin{tabular}{|ll|}
\hline Coitus frequency & Percentage \\
\hline Once a week & 21 \\
\hline Twice a week & 47 \\
\hline Thrice a week & 20 \\
\hline >Thrice a week & 12 \\
\hline
\end{tabular}

In the evaluation of infertility, a detailed sexual history has a significant role in the management. The awareness among the couple about fertile period and non-fertile period has a significant role in treating the infertility. As per the science, mature spermatozoa can retain its fertilising capacity from 24 to $48 \mathrm{hrs}$ in genital tract and ovum can retain its fertility capacity from 12 to $24 \mathrm{hrs}$. 
according to this equation sexual intercourse every day or every alternative day becomes mandatory in the fertile period. In present observational study, majority of the patients revealed that they are having coitus twice weekly $(47 \%)$, followed by once per week $(21 \%)$ (Table 2$)$.

More than thrice a week there were 12 patients which is scientifically acceptable coitus frequency.

Table 3: Distribution of cases according to the duration of abstinence in percentage.

\begin{tabular}{|l|l|}
\hline Duration of abstinence & Percentage \\
\hline $1-3$ days & 47 \\
\hline $3-7$ days & 35 \\
\hline $7-10$ days & 3 \\
\hline$>10$ days & 15 \\
\hline
\end{tabular}

As per the WHO guidelines, the ideal duration of abstinence is 72 hours in the primary evaluation of semen to nullify the errors which can happen in cases of abstinence which is either too short or too long. In author's andrology laboratory all the patients were subjected to semen analysis irrespective of days of abstinence from the sexual intercourse. According to this observational study majority of patients were $47 \%$ in the abstinence group of 1-3 days followed by $35 \%$ in 3-7 days. The least number of patients were in the 7-10 days group (Table 3 ).

\section{Table 4: Distribution of cases as per the presence of} chronic medical ailments in percentage.

\begin{tabular}{|ll|}
\hline Medical disorders & Percentage \\
\hline Diabetes mellitus & 3 \\
\hline Hypertension & 1 \\
\hline Diabetes melitus and hypertension & 3 \\
\hline Non diabetic and non hypertension & 93 \\
\hline
\end{tabular}

There is no scientific evidence to prove that diabetes or hypertension have a direct impact on quality or quantity of spermatozoa. But, these disorders can have indirect impact on sexual well-being either because of the disease itself or because of the medication. In present study, only $7 \%$ patients revealed that they are on treatment for either DM or hypertension or both. Surprisingly, $93 \%$ of the patients did not have history of DM, hypertension or both (Table 4).

Table 5: Patient distribution according to substance abuse in percentage.

\begin{tabular}{|ll|} 
Substance abuse & Percentage \\
\hline Smokers & 15 \\
\hline Tobacco chewers & 29 \\
\hline Alcoholics & 39 \\
$\begin{array}{l}\text { Non alcoholics, non smokers, non } \\
\text { abusers of substance }\end{array}$ & 17 \\
\hline
\end{tabular}

In this observational study, authors found that around $17 \%$ of patients were belonging to no substance abuse either in the form of tobacco chewing or alcohol consumption or smoking. Majority of the patients are alcoholics $39 \%$ followed by Tobacco chewers $29 \%$ (Table 5).

As per WHO, hyperspermia is considered when semen volume is $>6 \mathrm{ml}$, and hypospermia is diagnosed $<0.3 \mathrm{ml}$. In present observational study the semen volume per ejaculation were measured according to standard guidelines by WHO on semen analysis. Majority of patients i.e. $50 \%$, the semen volume was $1-2 \mathrm{ml}$, followed by $25 \%$ who were belonging to $2-3 \mathrm{ml}$ of semen volume per ejaculation group. Least number of patients were $5 \%$ in 3-6 ml group. None of the patients were either hypo or hyperspermia (Table 6).

Table 6: Distribution of patients as per semen volume in percentage.

\begin{tabular}{|ll|}
\hline Semen volume & Percentage \\
\hline $0.3-1 \mathrm{~mL}$ & 18 \\
\hline $1-2 \mathrm{~mL}$ & 50 \\
\hline $2-3 \mathrm{~mL}$ & 25 \\
$>3 \mathrm{~mL}$ & 5 \\
\hline
\end{tabular}

Liquefaction is the process where semen gets liquified after ejaculation to facilitate the ascent of spermatozoa after deposition in the posterior fornix during intercourse. According to WHO, the normal liquefaction time is considered to be less than 20 minutes. In present study majority of patients $77 \%$ have liquefaction time less than 20 minutes followed by $21 \%$ who have more than 60 minutes, none of the patients were in the fail to liquefy group (Table 7).

Table 7: Distribution of cases according to liquefaction time in percentage.

\begin{tabular}{|l|l|}
\hline Liquefaction time & Percentage \\
\hline$<20$ minutes & 77 \\
\hline $20-60$ minutes & 2 \\
\hline$>60$ minutes & 21 \\
\hline
\end{tabular}

The sperm concentration in the semen analysis is one parameter which has a significant role in clinical management. Normally, the sperm concentration is considered to be between 60 and 120 million $/ \mathrm{mL}$.

Less than 20 million is known to be oligozoospermia which is sub classified in to mild (10-20 million/mL), moderate (5-10 million $/ \mathrm{mL})$, severe (less than 5 million $/ \mathrm{mL}$ ). In present study majority $42 \%$ were in the normozoospermia group ( $>60 \mathrm{million} / \mathrm{mL})$, followed by $20 \%$ in $20-60$ million/mL group. The number of patients in oligozoospermic group were $18 \%$, in that $7 \%$ were in the moderate oligozoospermic group (Table 8). 
Table 8: Distribution of patients according to sperm concentration in percentage.

\begin{tabular}{|ll|}
\hline Sperm concentration & Percentage \\
\hline $5-10$ million $/ \mathrm{mL}$ & 7 \\
\hline $10-20$ million $/ \mathrm{mL}$ & 18 \\
\hline $20-60$ million $/ \mathrm{mL}$ & 20 \\
\hline$>60$ million $/ \mathrm{mL}$ & 42 \\
\hline Could not be assessed & 15 \\
\hline
\end{tabular}

A good percentage of motile sperm (40\%) is the direct indicator of good fertility status of a male partner in the infertility evaluation. The motility of sperms is likely to get affected by various direct and indirect factors like infection of the genital tract, smoking etc. In present study, majority of the patients were belonging to more than $80 \%$ group which is a good percentage group (47\%), followed by $19 \%$ who belonged to $30-60 \%$ group. But in $15 \%$ of cases they reported as motility could not be assessed without quoting the reasons (Table 9).

Table 9: Distribution of patients as per the sperm motility in percentage.

\begin{tabular}{|ll|}
\hline Total motility & Percentage \\
\hline Less than $40 \%$ & 7 \\
\hline $40-60 \%$ & 19 \\
\hline $60-80 \%$ & 12 \\
\hline$>80 \%$ & 47 \\
\hline Could not be assessed & 15 \\
\hline
\end{tabular}

In present study, authors found 57 cases out of hundred having normal morphology of $50 \%$ and above and 28 cases out of hundred having morphology of $50 \%$ and less, which could be considered as teratozoospermia. Teratozoospermia is one of the parameter in semen analysis is an indicator of male infertility (Table 10).

Table 10: Distribution of patients according to sperm morphology in percentage.

\begin{tabular}{|ll|}
\hline Sperm morphology & Percentage \\
\hline Normal morphology $>50 \%$ & 57 \\
\hline Abnormal morphology $<50 \%$ & 28 \\
\hline Could not be assessed & 15 \\
\hline
\end{tabular}

\section{DISCUSSION}

In present study which includes 100 cases of male infertile patients to determine abnormalities in semen analysis and other related factors which are having direct or indirect role as the fertility is concerned.

The most common age group of infertile male patients were under 30 years which corresponds to $40 \%$ but study conducted by Jajoo et al reported that majority of patients were $(56 \%)$ under 30 years of age group which is almost comparable to present study. ${ }^{4}$ Another study conducted by Jain et al reported that $50 \%$ of male infertile patients were belonging to under the age of 30 years which is also similar to our study report. ${ }^{5}$ In present study $6 \%$ patients were under the age group of 25 years, study conducted by Sunny reported that $4 \%$ of the patients were belonging to under 25 years age group which is similar to age group related incidence in our study. ${ }^{6}$

Sexual intercourse in the fertile period is one of the important factor for attaining pregnancy, in our study majority of patients (47\%) of patients had coitus frequency of twice a week followed by once a week in $21 \%$ of patients. In a study Perlis et al reported that median coital frequency was 7 per month which is almost similar to present study. ${ }^{7}$

In present study the most common abstinence duration was 1-3 days contributing to $47 \%$, as per study conducted by Pellestor et al reported that long abstinence period might induce senescence of spermatozoa. ${ }^{8}$

According to study by Pant smoking, testicular trauma and mumps were the common risk factors amongst the males of infertile couples, in our study in the risk factor assessment $15 \%$ were belonging to smokers group and $39 \%$ to alcohol group. ${ }^{9}$ According to Sharma et al found that heavy and moderate smokers had worse semen quality than mild smokers and non-smokers. ${ }^{10}$

As per present study around one-fourth of patients were in the hypospermia group (according to WHO $<1.5 \mathrm{ml}$ ), in a study conducted by Mama reported that $11.9 \%$ patients were in the hypospermia group which is almost half of the result what authors' reported. ${ }^{11}$

In present study, oligospermic patients were around 25\%, but study conducted in infertility clinic in Nigeria by Ugwuja et al reported the oligospermic incidence in the study population was $70 \%$ which is almost three times the incidence of what we have reported. ${ }^{12}$ A study conducted by Damsgaard et al reported in relation to oligospermia and varicocele that sperm concentration was negatively associated with the presence and increasing grade of varicocele and was more than halved, at 23 million/mL. ${ }^{13}$

Nallella et al did a study to compare the sperm concentration in proven fertile men and male factor infertility patient, the respective value they got is 69.9 and 21.3 with the $p$ value of $<0.001 .{ }^{14}$

According to $\mathrm{WHO}$, in the revised guidelines, total (progressive and non-progressive motility) of $40 \%$ is considered normal in semen analysis. In our study $7 \%$ of cases were in the lower motility group. In a study conducted by Jajoo et al reported that around $8 \%$ patients were in the less than $25 \%$ motility and $27 \%$ were in the 25-50 motility group. ${ }^{4}$ Overall, they reported that $35 \%$ patient had $<50 \%$ motile sperm/hpf. In contrast to concentration, evidence consistently indicates that sperm motility decreases with advancing age. ${ }^{15}$ 
Study conducted by Karabulut et al reported that progressive sperm motility decreases with decreasing sperm counts. While progressive and non-progressive motile sperm percentage decreases, non-motile sperm percentage increases under the sperm values of less than 15 million $/ \mathrm{mL}^{16}$

As per the WHO guidelines 4\% normal forms using strict TYGERBERG method considered as normal. But in present study all the patients are having more than $4 \%$ morphological forms. ${ }^{17}$

\section{CONCLUSION}

Semen analysis remains a crucial component in the evaluation of male infertility, in addition to brief sexual history and occupational history. Standardising the procedure including duration of abstinence, collection method, and analysis makes it a more clinically reliable tool for infertility evaluation. Patients with abnormal semen parameters were counselled for further treatment to attain a successful pregnancy.

Funding: No funding sources

Conflict of interest: None declared

Ethical approval: The study was approved by the Institutional Ethics Committee

\section{REFERENCES}

1. Kumar N, Singh AK. Trends of male factor infertility, an important cause of infertility: a review of literature. J Human Reprod Sci. 2015;8(4):191.

2. Lalitha C, Sayee R, Apoorva D. Environmental/occupational factors and seasonality of birth-male infertility. World academy of science, engineering and technology. Int J Med Health Sci. 2015;2(8).

3. Esteves SC. Clinical relevance of routine semen analysis and controversies surrounding the 2010 World Health Organization criteria for semen examination. Int Braz J Urol. 2014;40(4):433-53.

4. Jajoo S, Kalyani KR. Prevalence of abnormal semen analysis in patients of infertility at a rural setup in Central India. Int $\mathbf{J}$ Reprod Contracept Obstet Gynecol. 20169;2(2):161-4.

5. Jain A, Ambrish PI, Hoogar MB, Dhar R, Wani A, Agrwal S. Role of semen analysis in the diagnosis of infertility at a tertiary care centre in Western India: a prospective study. Int J Reprod Contracept Obstet Gynecol. 2017;5(7):2389-91.
6. Abarikwu SO. Causes and risk factors for malefactor infertility in Nigeria: a review. Afr J Reprod Health. 2013;17(4):150-66.

7. Perlis N, Lo KC, Grober ED, Spencer L, Jarvi K. Coital frequency and infertility: which male factors predict less frequent coitus among infertile couples?. Fertil Steril. 2013;100(2):511-5.

8. Pellestor F, Girardet A, Andreo B. Effect of long abstinence periods on human sperm quality. Int $\mathbf{J}$ Fertil Menopausal Stud. 1994;39(5):278-82.

9. P R Pant. Factors affecting male infertility. J Instit Med. 2010;32(2).

10. Sharma R, Harlev A, Agarwal A, Esteves, SC. Cigarette smoking and semen quality: A new metaanalysis examining the effect of the 2010 WHO laboratory methods for the examination of human semen. Eur Urol. 2016;70(4):635-45.

11. Diallo MS, Diallo AS, Fotso P, Diallo Y, Diao B, Faye O. Semen Abnormality Patterns and Parameters in Male Partners of Infertile Couples in Dakar (Senegal). Open J Urol. 2015;5(09):155.

12. Ugwunja EP, Ugwa NC, Prevalence of low sperm count and abnormal semen parameters in male partners of women consulting at infertility clinic in Abakaliki, Nigeria. Afr J Reprod Health. 2005;12(1):67-73.

13. Damsgaard J, Joensen UN, Carlsen E, Erenpreiss J, Jensen MB, Matulevicius V, et al. Varicocele is associated with impaired semen quality and reproductive hormone levels: a study of 7035 healthy young men from six European countries. Eur Uro. 2016;70(6):1019-29.

14. Nallella KP, Sharma RK, Aziz N, Agarwal A. Significance of sperm characteristics in the evaluation of male infertility. Fertil Steril. 2006;85(3):629-34.

15. Harris ID, Fronczak C, Roth L, Fertility and the aging male. Rev Urol. 2011;13(4):e184-90.

16. Karabulut A, Tekin A, Alterations in the morphology and motility of spermatozoa: relation with total sperm count Pam Med J. 2013;6(1):1-4.

17. World Health Organization Department of reproductive health and research. WHO Laboratory Manual for the examination and processing of human semen 5th edition, Geneva, Switzerland: WHO 2010.

Cite this article as: Ganiga $P$, Pujeri S. Study on semen analysis in the evaluation of male infertility in coastal Karnataka, India. Int J Reprod Contracept Obstet Gynecol 2018;7:2603-7. 